\title{
Do medical students copy the drug treatment choices of their teachers or do they think for themselves?
}

\author{
J. Tichelaar • M. C. Richir • H. J. Avis • H. J. Scholten • \\ N. F. Antonini • Th. P. G. M. De Vries
}

Received: 27 April 2009 / Accepted: 1 October 2009/Published online: 24 November 2009

(C) The Author(s) 2009. This article is published with open access at Springerlink.com

\begin{abstract}
Purpose Although the importance of rational prescribing is generally accepted, the teaching of pharmacotherapy to undergraduate medical students is still unsatisfactory. Because clinical teachers are an important role model for medical students, it is of interest to know whether this extends to therapeutic decision-making. The aim of this study was to find out which factors contribute to the drug choices made by medical students and their teachers (general practitioners and clinical specialists).

Methods Final-year medical students $(n=32)$, and general practitioners $(n=29)$, lung specialists $(n=26)$, orthopaedic surgeons $(n=24)$, and internists $(n=24)$ serving as medical teachers from all eight medical schools in the Netherlands participated in the study. They were asked to prescribe treatment (drug or otherwise) for uncomplicated (A) and complicated (B) written patient cases and to indicate which factors influenced their choice of treatment, using a list of factors reported in the literature to influence drug prescribing. Results Final-year medical students primarily based their drug choice on the factors 'effectiveness of the drugs' and 'examples from medical teachers'. In contrast, clinical teachers primarily based their drug choice on the factors 'clinical experience', 'effectiveness of the drugs', 'side effects of the drugs', 'standard treatment guidelines', and 'scientific literature'.

Conclusions Medical teachers would appear to base their drug choice mainly on clinical experience and drug-related factors, whereas final-year medical students base their drug
\end{abstract}

J. Tichelaar and M. C. Richir contributed equally to this work.

J. Tichelaar • M. C. Richir $\cdot$ H. J. Avis $\cdot$ H. J. Scholten

N. F. Antonini - T. P. G. M. De Vries $(\square)$

Department of Clinical Pharmacology and Pharmacy,

VU University Medical Center,

De Boelelaan 1118, PK1X74, 1081 HV Amsterdam,

The Netherlands

e-mail: thpgm.devries@vumc.nl choice mainly on examples provided by their medical teachers. It is essential that medical teachers clearly explain to their students how they arrive at a specific choice of medication since medical students tend to copy the therapeutic drug choices from their teachers, mainly because of a lack of experience. Presenting students with clinical therapeutic problems early during undergraduate training will not only give them a chance to gain experience in solving medical problems but will also give meaning to what they are studying as opposed to merely reproducing what they learn or copying what they are told.

Keywords Therapeutic reasoning · Drug treatment choice . Undergraduate teaching $\cdot$ Medical students .

Pharmacotherapy

\section{Introduction}

Unlike diagnostic reasoning [1,2], little is known about therapeutic reasoning, the process by which doctors make a choice of treatment [3]. This part of the consultation is often regarded simply as a matter of knowing which drug to prescribe for a certain condition rather than as a reasoned choice [4]. Experienced doctors rely on their knowledge when prescribing drugs for common ailments $[4,5]$, often having two to five potential drug and non-drug treatments for the disease or symptom(s) in their mental 'standard treatment guideline'. They make their choice of these options heuristically [6]. This means that doctors may not be conscious of the assumed value judgement and logic underlying their therapeutic decision. In turn, this lack of awareness may make it difficult for medical teachers to explain to medical students how they arrive at a certain therapeutic choice. In addition, teaching in clinical disciplines tends to be focussed on symptoms and making an appropriate 
diagnosis, and relatively little attention is paid to the principles of drug treatment or pharmacotherapy [3]. This may explain in part why many graduates feel under-prepared to take on prescribing responsibilities after graduation [7].

In order to gain insight into the therapeutic decisionmaking process, we investigated whether there are differences in the factors contributing to the drug choices of final-year medical students and their teachers (general practitioners and clinical specialists).

\section{Materials and methods}

Final-year medical students and medical teachers in four clinical specialities (general practice, pulmonology, orthopaedics, and internal medicine) from all eight medical schools in the Netherlands participated in this study. The heads of the above-mentioned departments were asked to select five specialists to participate and in addition the heads of the departments of general practice were asked to select randomly eight final-year medical students (because general practice medicine is the last clerkship before graduation).

Three clinical patient cases (bronchial asthma, osteoarthritis and essential hypertension) with two levels of complexity (A and B) were developed in consultation with clinical specialists and clinical pharmacologists from the VU University Medical Center in Amsterdam, the Netherlands
(Table 1). Cases identified as A were uncomplicated, whereas $\mathrm{B}$ was a more complicated version of $\mathrm{A}$ involving comorbidity and comedication. The participants recorded their choice of drug and/or non-drug treatment on a form. The pulmonology, orthopaedics and internal medicine specialists completed the patient cases for their own specialty only, whereas the general practitioners and the final-year medical students completed all three patient cases.

After the participants had made their treatment choice, they were given a list of drug choice-related factors (see below) that are mentioned in the literature as contributing to therapeutic decision-making [5, 6, 8-11]. The participants were asked to indicate to what extent each of the 14 factors had contributed to the choice of treatment for each patient case $(0=$ to no extent at all, $1=$ to some extent, $2=$ to a considerable extent, $3=$ to a decisive extent).

\section{Data collection and statistical analysis}

The generic names of drugs were used, and prescribed drugs were classified into groups according to the Dutch Pharmacotherapy Compendium [12]. The primary outcome scores on drug choice-related factors were described by means including $95 \%$ confidence intervals. A one-way ANOVA in combination with a least-squared difference test was performed to investigate the differences in each drug choice-related factor among the students, general practitioners

Table 1 Summary of the written patient cases presented to the participants for choosing a (drug) treatment

\begin{tabular}{|c|c|c|}
\hline Patient case & $\begin{array}{l}\text { Uncomplicated (A) vs } \\
\text { complicated (B) }\end{array}$ & Situated in general practice or the outpatient clinic \\
\hline \multirow[t]{4}{*}{ Bronchial asthma } & A & Woman, age 22. History: - \\
\hline & & $\begin{array}{l}\text { Currently: Acute asthma attack a few hours ago, lasting about } 5 \mathrm{~min} . \\
\text { Works in pet shop. Working diagnosis: bronchial asthma }\end{array}$ \\
\hline & $\mathrm{B}$ & $\begin{array}{l}\text { Woman, age } 22 \text {. History: migraine for } 6 \text { months. Takes acetaminophen } \\
2 \times 500 \mathrm{mg} \text { and metoclopramide supp. } 20 \mathrm{mg} \text { during migraine attack. } \\
\text { No attacks since using propranolol tab. } 80 \mathrm{mg} \text { daily }\end{array}$ \\
\hline & & $\begin{array}{l}\text { Currently: Acute asthma attack a few hours ago, lasting about } 5 \mathrm{~min} \text {. } \\
\text { Works in pet shop. Working diagnosis: bronchial asthma }\end{array}$ \\
\hline \multirow[t]{4}{*}{ Osteoarthritis } & A & Woman, age 63. History: - \\
\hline & & Currently: increasing pain in right knee for a few weeks. Working diagnosis: osteoarthritis \\
\hline & $\mathrm{B}$ & $\begin{array}{l}\text { Woman, age } 61 . \text { History: osteoarthritis in right knee for } 10 \text { years. } \\
\text { Ibuprofen tab. } 400 \mathrm{mg} \text { when necessary for 1year; no pain }\end{array}$ \\
\hline & & Currently: stomach pain for 7days. Working diagnosis: NSAID-related gastric symptoms \\
\hline \multirow[t]{4}{*}{ Essential hypertension } & A & Woman, age 52. History: - \\
\hline & & $\begin{array}{l}\text { Currently: high blood pressure detected during a sports physical examination. } \\
\text { No complaints. Now: BP } 160 / 105 \mathrm{mmHg} \text {. Working diagnosis: essential hypertension }\end{array}$ \\
\hline & $\mathrm{B}$ & $\begin{array}{l}\text { Man, age } 62 \text {. History: myocardial infarction in } 1999 \text {. Since then: atenolol } \\
\text { 50mg daily, acetosal } 80 \mathrm{mg} \text { daily. Six weeks ago: recurrent high blood pressure } \\
\text { 170/105mmHg; diet and exercise advice }\end{array}$ \\
\hline & & $\begin{array}{l}\text { Currently: control visit: BP 170/100mmHg. Working diagnosis: essential hypertension, } \\
\text { after } 6 \text { weeks of not responding to diet, exercise advice and atenolol }\end{array}$ \\
\hline
\end{tabular}


Table 2 The treatments prescribed (\%) by students, general practitioners and specialists for the uncomplicated (A) and complicated (B) cases

\begin{tabular}{|c|c|c|c|c|c|c|c|c|}
\hline & & & $\begin{array}{l}\text { Final-year medical } \\
\text { students }(n=32)\end{array}$ & Percentage & $\begin{array}{l}\text { General practitioners } \\
(n=29)\end{array}$ & Percentage & $\begin{array}{l}\text { Clinical specialists } \\
(n=26,24,24)\end{array}$ & Percentage \\
\hline \multirow{9}{*}{$\begin{array}{l}\text { Bronchial } \\
\text { asthma }\end{array}$} & \multirow[t]{3}{*}{$\mathrm{A}$} & 1 & $\beta_{2}$ agonist & 90 & $\beta_{2}$ agonist & 94 & $\beta_{2}$ agonist & 52 \\
\hline & & 2 & $\beta_{2}$ agonist + steroid & 5 & $\beta_{2}$ agonist + steroid & 6 & $\beta_{2}$ agonist + steroid & 44 \\
\hline & & 3 & Other & 5 & & & Other & 4 \\
\hline & \multirow[t]{6}{*}{$\mathrm{B}$} & 1 & $\beta_{2}$ agonist & 40 & $\beta_{2}$ agonist & 41 & $\beta_{2}$ agonist + steroid & 40 \\
\hline & & 2 & Steroid & 25 & $\beta_{2}$ agonist + steroid & 24 & $\beta_{2}$ agonist & 20 \\
\hline & & 3 & $\mathrm{~B}_{2}$ agonist + steroid & 20 & $\begin{array}{l}\beta_{2} \text { agonist }+ \text { steroid }+ \text { stop } \\
\text { beta antagonist }\end{array}$ & 24 & $\begin{array}{l}\beta_{2} \text { agonist }+ \text { stop beta } \\
\text { antagonist }\end{array}$ & 8 \\
\hline & & 4 & Other & 15 & Other & 11 & $\begin{array}{l}\beta_{2} \text { agonist }+ \text { steroid }+ \text { stop } \\
\text { beta antagonist }\end{array}$ & 8 \\
\hline & & & & & & & $\begin{array}{l}\beta_{2} \text { agonist }+ \text { steroid }+ \\
\text { prednisone }\end{array}$ & 8 \\
\hline & & & & & & & Other & 16 \\
\hline \multirow[t]{9}{*}{ Osteoarthritis } & \multirow[t]{4}{*}{ A } & 1 & $\begin{array}{l}\text { Prostaglandin } \\
\text { inhibitor }\end{array}$ & 60 & Non-opioid analgesics & 53 & Prostaglandin inhibitor & 70 \\
\hline & & 2 & $\begin{array}{l}\text { Non-opioid } \\
\text { analgesics }\end{array}$ & 25 & Prostaglandin inhibitor & 30 & Prostaglandin inhibitor + PPI & 13 \\
\hline & & 3 & Prostaglandin & 15 & Prostaglandin inhibitor + PPI & 17 & Non-opioid analgesics & 13 \\
\hline & & & inhibitor + PPI & & & & Other & 4 \\
\hline & \multirow[t]{5}{*}{ B } & 1 & PPI & 40 & Non-opioid analgesics & 61 & PPI & 35 \\
\hline & & 2 & $\begin{array}{l}\text { Prostaglandin } \\
\text { inhibitor + PPI }\end{array}$ & 35 & Prostaglandin inhibitor + PPI & 17 & Non-opioid analgesics & 22 \\
\hline & & 3 & $\begin{array}{l}\text { Prostaglandin } \\
\text { inhibitor }\end{array}$ & 10 & Prostaglandin inhibitor & 11 & Prostaglandin inhibitor + PPI & 17 \\
\hline & & 4 & Opioid & 5 & PPI & 11 & Prostaglandin inhibitor & 13 \\
\hline & & 5 & Other & 10 & & & Other & 13 \\
\hline \multirow{10}{*}{$\begin{array}{l}\text { Essential } \\
\text { hypertension }\end{array}$} & \multirow[t]{5}{*}{$\mathrm{A}$} & 1 & Diuretics & 50 & Diuretics & 42 & Beta antagonist & 36 \\
\hline & & 2 & Beta antagonist & 41 & Lifestyle advice & 27 & Diuretics & 28 \\
\hline & & 3 & Lifestyle advice & 9 & Beta antagonist & 26 & Lifestyle advice & 24 \\
\hline & & & & & ACE inhibitor & 5 & ACE inhibitor & 8 \\
\hline & & & & & & & Calcium antagonist & 4 \\
\hline & \multirow[t]{5}{*}{$\mathrm{B}$} & 1 & Diuretics & 46 & Beta antagonist & 48 & Beta antagonist & 44 \\
\hline & & 2 & ACE inhibitor & 23 & Diuretics & 26 & ACE inhibitor & 24 \\
\hline & & 3 & Beta antagonist & 18 & ACE inhibitor & 21 & Diuretics & 12 \\
\hline & & 4 & Lifestyle advice & 9 & Lifestyle advice & 5 & Beta antagonist + diuretics & 12 \\
\hline & & 5 & Other & 4 & & & Other & 8 \\
\hline
\end{tabular}

PPI Proton pump inhibitor

and clinical specialists. We also compared the students versus medical teachers (i.e. general practitioners and specialists). The model assumptions were investigated by residual analysis. A $P$-value $<0.05$ was considered statistically significant. Statistical analyses were performed using SPSS 15.0 (SPSS, Chicago, IL).

\section{Results}

Thirty-two final-year medical students, 29 general practitioners and 74 clinical specialists (26 lung specialists, 24 orthopaedic surgeons and 24 internists) participated in the study. They prescribed 128, 116 and 148 drug and non-drug treatments respectively (see Table 2). In general, the drugs prescribed by medical students and general practitioners were similar, whereas clinical specialists prescribed relatively more potent drugs out of a broader range of drug classes.

The contribution of the various factors to the drug choice of the students, general practitioners and clinical specialists is shown in Table 3. Since there was no difference in the factors influencing the choice of treatment for $\mathrm{A}$ and $\mathrm{B}$ cases, the scores of the two versions were pooled. Students based their drug choice to a considerable extent (mean score $\geq 2$ on a scale of $0-3$ ) on the factors 'effectiveness of the drugs' and 'examples from clinical teachers'. In 
Table 3 Importance of factors affecting drug choice, as rated by students, general practitioners and clinical specialists

\begin{tabular}{|c|c|c|c|c|}
\hline & $\begin{array}{l}\text { Final-year } \\
\text { medical students } \\
(n=32)\end{array}$ & $\begin{array}{l}\text { General } \\
\text { practitioners } \\
(n=29)\end{array}$ & $\begin{array}{l}\text { Clinical } \\
\text { specialists } \\
(n=26,24,24)\end{array}$ & $\begin{array}{l}\text { ANOVA } \\
\text { overall } p \text {-value }\end{array}$ \\
\hline \multicolumn{5}{|l|}{ Practice-related factors } \\
\hline Own clinical experience & $1.59(1.40-1.79)$ & $2.32(2.19-2.45)^{\mathrm{b}}$ & $2.06(1.94-2.17)^{\mathrm{b}}$ & $<0.001$ \\
\hline $\begin{array}{l}\text { Easy administration } \\
\text { of the drug(s) }\end{array}$ & $1.00(0.83-1.17)$ & $1.08(0.88-1.29)$ & $0.92(0.77-1.07)$ & 0.34 \\
\hline Patients' convenience & $1.57(1.39-1.76)$ & $1.90(1.73-2.06)^{\mathrm{b}}$ & $1.83(1.70-1.96)^{\mathrm{b}}$ & 0.013 \\
\hline Compliance of the patient & $1.44(1.28-1.60)$ & $1.79(1.62-1.96)^{\mathrm{b}}$ & $1.78(1.64-1.91)^{\mathrm{b}}$ & 0.002 \\
\hline \multicolumn{5}{|l|}{ Drug-related factors } \\
\hline Effectiveness of the drug(s) & $2.19(2.07-2.31)$ & $2.28(2.14-2.41)$ & $2.50(2.40-2.60)^{\mathrm{b}}$ & $<0.001$ \\
\hline Side effects of the drug(s) & $1.55(1.38-1.73)$ & $2.19(2.01-2.37)^{\mathrm{b}}$ & $2.00(1.86-2.13)^{\mathrm{b}}$ & $<0.001$ \\
\hline Costs of the $\operatorname{drug}(\mathrm{s})$ & $0.88(0.72-1.04)$ & $1.40(1.21-1.59)^{\mathrm{b}}$ & $0.96(0.83-1.09)$ & $<0.001$ \\
\hline $\begin{array}{l}\text { Therapeutic spectrum } \\
\text { of the } \operatorname{drug}(\mathrm{s})\end{array}$ & $1.05(0.89-1.21)$ & $1.64(1.44-1.84)^{\mathrm{b}}$ & $1.67(1.52-1.82)^{\mathrm{b}}$ & $<0.001$ \\
\hline \multicolumn{5}{|l|}{ Information-related factors } \\
\hline $\begin{array}{l}\text { Standard treatment } \\
\text { guidelines (STG) }\end{array}$ & $1.98(1.82-2.14)$ & $2.17(1.99-2.35)$ & $1.73(1.58-1.87)^{\mathrm{b}}$ & $<0.001$ \\
\hline Scientific literature & $1.23(1.05-1.48)$ & $1.51(1.31-1.71)$ & $2.10(1.98-2.23)^{\mathrm{b}}$ & $<0.001$ \\
\hline The opinion of colleagues & $1.18(1.02-1.34)$ & $0.78(0.60-0.95)^{\mathrm{b}}$ & $1.10(0.97-1.24)$ & 0.001 \\
\hline $\begin{array}{l}\text { Information from the } \\
\text { pharmaceutical industry }\end{array}$ & $0.60(0.45-0.74)$ & $0.34(0.23-0.46)^{\mathrm{b}}$ & $0.81(0.69-0.93)^{\mathrm{b}}$ & $<0.001$ \\
\hline \multicolumn{5}{|l|}{ Teaching-related factors } \\
\hline Examples from clinical teachers & $2.06(1.93-2.20)^{\mathrm{a}}$ & $0.60(0.45-0.76)$ & $1.08(0.93-1.23)$ & $<0.001$ \\
\hline $\begin{array}{l}\text { Education and } \\
\text { postgraduate education }\end{array}$ & $1.30(1.11-1.48)$ & $1.68(1.50-1.86)^{\mathrm{b}}$ & $1.30(1.15-1.44)$ & 0.003 \\
\hline
\end{tabular}

Pooled data are presented as mean $(95 \% \mathrm{CI})$. Differences among groups were analysed by means of the least-squared difference test: ${ }^{\text {a }} P<0.05$ students vs. general practitioners and clinical specialists, ${ }^{\mathrm{b}} P<0.05$ vs. students

Factors with a score of score $\geq 2$ on a scale of $0-3$ were considered to have contributed to a considerable extent to the drug choice

contrast, both general practitioners and clinical specialists based their drug choice to a considerable extent on the factors 'clinical experience', 'effectiveness of the drug(s)', and 'side effects of the drug(s)'. In addition, general practitioners based their drug choice to a considerable extent on 'standard treatment guidelines' and clinical specialists on 'scientific literature'.

Students attached significantly more importance to 'examples from clinical teachers' when making their treatment choice than did the general practitioners and clinical specialists, whereas general practitioners and clinical specialists placed more emphasis on three practice-related factors ('own clinical experience', 'patients' convenience' and 'compliance of the patient') and two drug-related factors ['side effects of the $\operatorname{drug}(\mathrm{s})$ ' and 'therapeutic spectrum of the drug(s)']. Besides this, the general practitioners attached significantly more importance to the drug choice-related factors 'costs of the $\operatorname{drug}(\mathrm{s})$ ' and 'education and postgraduate education' compared to the students, whereas the clinical specialists rated the drug-related factors 'effectiveness of the drug(s)', 'scientific literature', and 'information from the pharmaceutical industry' significantly higher than the students.

\section{Discussion}

We found that medical teachers base their drug choice mainly on the factors 'clinical experience', 'effectiveness of the $\operatorname{drug}(\mathrm{s})$ ', 'side effects of the drug(s)', 'standard treatment guidelines' and 'scientific literature', whereas final-year medical students base their drug choice mainly on the factors 'effectiveness of the drug(s)' and 'examples from clinical teachers'. That medical teachers base their choice mainly on 'clinical experience' is consistent with theories from cognitive psychology about how clinical (diagnostic) expertise is achieved [2, 3, 13]. During everyday practice, doctors build up so-called cognitive networks of organised (therapeutic) knowledge and expertise [3], generating readily accessible treatment scripts. When a doctor is presented with a patient with one or more ailments, a specific treatment script is selected, depending on the level of complexity of the problem and the doctor's prior experience. This selection is done subconsciously when the medical problem is simple but occurs in a conscious and analytical way when the medical problem is complex. 
While both medical teachers and medical students based their choice of treatment on the 'effectiveness of the drug (s)', students' knowledge of drug effectiveness is mainly theoretical, since they have little or no prescribing experience, whereas medical teachers' knowledge of drug effectiveness is both theoretical and practical, based on the response of other patients to the medication in question. The same also holds for drug side effects: students have theoretical knowledge whereas medical teachers have both theoretical and practical knowledge. This practical knowledge gained through experience is probably why medical teachers rated this factor significantly higher than medical students.

Clinical specialists, in contrast to the general practitioners, rated the drug choice-related factor 'scientific literature' significantly higher than medical students. This might reflect a difference in patient populations seen by the two groups of medical teachers. Clinical specialists are accustomed to treating more complicated and severely ill patients who are, for the most part, referred by the general practitioner. In these cases, they frequently prescribe more potent and newer drugs [14]. Clinical specialists learn about these new drugs (mostly before their launch) from drug company advertising, the literature or at meetings [15]. This could account also, at least partly, for the significantly higher value assigned by clinical specialists to the drug choice-related factor 'information from the pharmaceutical industry'. General practitioners, in contrast to clinical specialists, based their drug choice to a considerable extent on the drug choice-related factor 'standard treatment guidelines'. These guidelines, which have been formulated for many common ailments and diseases, provide evidence-based recommendations for the treatment of 'standard' patients. In the Netherlands, general practitioners have a so-called gatekeeper function with regard to specialist care, and the use of national guidelines ensures a more uniform referral practice. Conversely, clinical specialists might possibly adhere more to international guidelines.

That students nearing graduation based their treatment choices on the example of their medical teachers is consistent with the copying behaviour of medical students $[16,17]$. Medical students have little opportunity to gain therapeutic experience, and so their reliance on the example of their teachers is not surprising. This means that clinical teachers need to explain the arguments underlying their treatment choice explicitly to their students $[18,19]$.

Before interpreting the results, the strengths and limitations of this study need to be addressed. As far as we know, this is the first nationwide study to investigate whether there are differences between medical students and their teachers in how they choose a medication. While we included 103 clinical teachers, we had only 32 final-year students. This was unfortunately inevitable because data collection occurred at one moment during the students' final clerkship, general practice. However, the students were recruited from all eight medical schools in the Netherlands, and since there were no significant differences in baseline characteristics (i.e. gender, age, etc.) or mean examination score during training, it is very likely that the included population was representative. Lastly, it may not be possible to generalise these results to medical students and teachers in other countries because of differences between medical curricula in various countries. However, our findings may be generalisable to medical students in countries that have a sequentially designed medical curriculum as in the Netherlands.

In conclusion, we found that final-year medical students base their prescribing choices on the examples of their teachers. To improve rational prescribing, medical curricula should pay more attention not only to diagnostic reasoning but also to therapeutic reasoning. Incorporation of specific clinical pharmacology and therapeutics courses into the medical curriculum [20] may help students bridge the gap between (pre-clinical) theoretical learning and (clinical) practical learning, and between undergraduate and postgraduate training. Presenting students with clinical therapeutic problems early during undergraduate training will not only give them a chance to gain experience in solving medical problems but will also give meaning to what they are studying as opposed to merely reproducing what they learn or copying what they are told [21, 22]. Replication of our findings in further studies might provide more insight into the process of therapeutic reasoning and contribute to optimisation of the therapeutic training of our future doctors.

Acknowledgments The authors thank the heads of the departments of pulmonology, orthopaedics and internal medicine, as well as the clinical pharmacologists of the VU University Medical Center for offering their expertise to the development of the clinical patient cases. We also thank the clinicians and students from all eight medical schools in the Netherlands for participating in this study.

Open Access This article is distributed under the terms of the Creative Commons Attribution Noncommercial License which permits any noncommercial use, distribution, and reproduction in any medium, provided the original author(s) and source are credited.

\section{References}

1. Regehr G, Norman GR (1996) Issues in cognitive psychology: implications for professional education. Acad Med 71(9):9881001

2. Schmidt HG, Norman GR, Boshuizen HP (1990) A cognitive perspective on medical expertise: theory and implication. Acad Med 65(10):611-621

3. Richir MC, Tichelaar J, Geijteman EC, de Vries TP (2008) Teaching clinical pharmacology and therapeutics with an emphasis on the therapeutic reasoning of undergraduate medical students. Eur J Clin Pharmacol 64(2):217-224 
4. de Vries TP (1993) Presenting clinical pharmacology and therapeutics: a problem based approach for choosing and prescribing drugs. Br J Clin Pharmacol 35(6):581-586

5. Denig P, Haaijer-Ruskamp FM (1992) Therapeutic decision making of physicians. Pharm World Sci 14(1):9-15

6. Denig P (1994) Drug choice in medical practice. Rationales, routines, and remedies. $\mathrm{PhD}$ Thesis, University of Groningen, Groningen

7. Han WH, Maxwell SR (2006) Are medical students adequately trained to prescribe at the point of graduation? Views of first year foundation doctors. Scott Med J 51(4):27-32

8. Denig P, Haaijer-Ruskamp FM, Wesseling H, Versluis A (1993) Drug expectations and drug choices of hospital physicians. J Intern Med 234(2):155-163

9. Denig P, Haaijer-Ruskamp FM, Zijsling DH (1988) How physicians choose drugs. Soc Sci Med 27(12):1381-1386

10. Janknegt R, Steenhoek A (1997) The system of objectified judgement analysis (SOJA). A tool in rational drug selection for formulary inclusion. Drugs 53(4):550-562

11. Wierenga B, Jong SJ, Mantel AF (1989) The decision making process of the family physician in choosing a drug. Ned Tijdschr Geneeskd 133(3):115-122

12. Loenen AC (2007) Pharmacotherapeutic compass. College voor Zorgverzekeringen, Amstelveen

13. Bissessur SW, Geijteman ECT, Al-dulaimy M, Teunissen PW, Richir MC, Arnold AER, Vries de TP (2009) Therapeutic reasoning: from hiatus to hypothetical model. J Eval Clin Pract (in press)
14. Jones MI, Greenfield SM, Bradley CP (2001) Prescribing new drugs: qualitative study of influences on consultants and general practitioners. BMJ 323(7309):378-381

15. Jones GL, Walley T, Bligh J (1997) Integrating clinical pharmacology in a new problem based medical undergraduate curriculum. Br J Clin Pharmacol 43:15-19

16. Garbutt JM, DeFer TM, Highstein G, McNaughton C, Milligan P, Fraser VF (2006) Safe prescribing: an educational intervention for medical students. Teach Learn Med 18(3):244-250

17. Rogers E (2003) Diffusion of innovations, 5th edn. Free Press, New York

18. Orme M, Sjoqvist F, Bircher J, Bogaert M, Dukes MN, Eichelbaum M, Gram LF, Huller H, Lunde I, Tognoni G (1990) The teaching and organisation of clinical pharmacology in European medical schools (W.H.O. Working Group on Clinical Pharmacology). Eur J Clin Pharmacol 38(2):101-105

19. Orme M, Reidenberg M (1989) The teaching of clinical-pharmacology in Europe and North-America. Trends Pharmacol Sci 10(6):224-226

20. Richir M, Tichelaar J, Stam F, Thijs A, Danner S, Schneider A, de Vries T (2008) A context-learning pharmacotherapy program for preclinical medical students leads to more rational drug prescribing during their clinical clerkship in internal medicine. Clin Pharmacol Ther 84(4):513-516

21. Marton F, Säljö R (1976) On qualitative differences in learning I: outcome and process. Brit J Educ Psych 46:4-11

22. Marton F, Säljö R (1976) On qualitative differences in learning II: outcome as a function of the learner's conception of the task. Brit J Educ Psych 46:115-127 